\section{Plasma concentrations of ropivacaine given with or without epinephrine for brachial plexus block}

Rosemary Hickey MD,* Janna Blanchard MD,* Joan Hoffman RN MSN,* Jan Sjovall PhD, $\dagger$ Somayaji Ramamurthy MD*
The purpose of this study was to determine the pharmacokinetic properties of the local anaesthesic ropivacaine used with or without epinephrine for brachial plexus block. Seventeen ASA physical status I or II adult patients undergoing elective orthopaedic surgery received a single injection of $33 \mathrm{ml}$ ropivacaine for subclavian perivascular block and $5 \mathrm{ml}$ to block the intercostobrachial nerve in the axilla. One group $(\mathrm{n}=8)$ received 0.5 per cent ropivacaine without epinephrine $(190 \mathrm{mg})$ and the other $(\mathrm{n}=9)$ received 0.5 per cent ropivacaine with epinephrine $1: 200,000$ (190 mg). Plasma ropivacaine concentrations were measured from peripheral venous blood samples taken for 12 hr after drug administration. Ropivacaine base was determined in plasma using gas chromatography and a nitrogen-sensitive detector. The mean peak plasma concentration $\left(C_{\text {mar }}\right.$ ) was $1.6 \pm 0.6 \mathrm{mg} \cdot \mathrm{L}^{-1}$ and $1.3 \pm 0.4 \mathrm{mg} \cdot \mathrm{L}^{-1}$ after administration of ropivacaine with and without epinephrine. The median time to peak plasma concentration ( $t_{\text {mar }}$ ) was 0.75 $\mathrm{hr}$ and $0.88 \mathrm{hr}$ and the mean area under the plasma concentration curve $A \cup C_{0.12 \mathrm{~h}}$ was $7.7 \pm 3.6$ and $7.0 \pm 3.4 \mathrm{mg} \cdot 1 \mathrm{hr}^{-1}$. The differences were not statistically significant. The terminal phase of the individual plasma concentration-fime curves

\section{Key words}

ANAESTHETICS, LOCAL: ropivacaine; ANAESTHETIC TECHNIQUES: regional, brachial plexus; PHARMACOKINETICS: ropivacaine.

*From the Department of Anesthesiology, University of Texas Health Science Center at San Antonio, 7703 Floyd Curl Drive, San Antonio, Texas 78284, and †Astra Pain Control, Clinical Pharmacology, S-I5I 85 Sodertalje-Sweden.

The study was supported by a grant from Astra Pain Control and was conducted at Audie L. Murphy Memorial Veteran's Administration Hospital and Medical Center Hospital in San Antonio, Texas.

Address correspondence to: Dr. Rosemary Hickey, The University of Texas Health Science Center at San Antonio, 7703 Floyd Curl Drive, San Antonio, Texas 78284-7838. showed a varying and sometimes slow decline possibly indicating a sustained systemic uptake of ropivacaine from the brachial plexus. No central nervous system or cardiovascular symptoms attributed to systemic plasma concentrations of the drug were observed, with the dose $\left(1.90-3.28 \mathrm{mg} \cdot \mathrm{kg}^{-1}\right)$ of ropivacaine used. It is concluded that the addition of epinephrine does not alter the pharmacokinetic properties of ropivacaine when used for subclavian perivascular brachial plexus block.

Le but de cet étude était de dérerminer la pharmacocinérique de l'anesthésique local ropivacaine urilisé avec ou sans épinéphrine pour un bloc de plexus brachiale. Dix-sept patients adulles ASA I ou 2 devant subir des chirurgies orthopédiques électives ont reçu une injection unique de $33 \mathrm{ml}$ de ropivacaine pour un bloc périvasculaire sous clavière $5 \mathrm{ml}$ afin de bloquer le nerf intercostal brachial à l'aisselle. Un groupe $(\mathbf{n}=8)$ a reçu 0.5 pour cent de ropivacaine sans épinéphrine $(190 \mathrm{mg})$ et l' autre (n = 9) a reçu 0,5 pour cent de ropivacaine avec épinéphrine l:200,000 (190 mg). Les concentrations plasmatiques de ropivacaine ont été mesurées à partir d'échantillons veineux périphériques 12 heures après l'administration de la drogue. La base de ropivacaine a été déterminée dans le plasma utilisant la chromotographie et un détecteur sensible à l'azote. Les concentrations plasmatiques mayennes les plus élevées $\left(C_{\max }\right)$ étail de $1,6 \pm 0,6 \mathrm{mg} \cdot \mathrm{L}^{-1}$ et $1,3 \pm 0,4 \mathrm{mg} \cdot \mathrm{L}^{-1}$ après administration de ropivacaine avec ou sans épinéphrine. Le temps moyen pour atteindre la concentration plasmatique maximale $\left(I_{\text {mar }}\right)$ étair de 0,75 heures et 0,88 heures vu la moyenne de la surface sous la courbe de concentration plasmatique $A \cup C_{0.12 \mathrm{~h}}$ élail de $7,7 \pm 3,6$ et 7,0 $3,4 \mathrm{mg} \cdot 1 \mathrm{hr}^{-1-1}$. Les différences n'éraient pas statistiquement significatives. La phase terminale des courbes des concentrations plasmatiques-temps ont démontré un déclin variable el des fois lent indiquant possiblememt une rétention systémique soutenue ds ropivacaine à partir du plexus brachial. Aucun symptôme cardiovasculaire ou nerveux central attribué aux concentrations plasmatiques de la drogue furent observé avec des doses de $\left(I, 90-3,28 \mathrm{mg} \cdot \mathrm{kg}^{-I}\right)$ de ropivacaine utilisée. On conclut que l'addition d' épinéphrine n' altère pas la pharmacocinétique de la ropivacaine lorsqu' utilisée pour un bloc de plexus brachial. 
Ropivacaine is an amide-type local anaesthetic primarily intended for peripheral nerve blockade and epidural anaesthesia. It is used as the hydrochloride monohydrate of the (S)-enantiomer and has a pKa of 8.1. The uptake of ropivacaine into human subcutaneous and epidural fat in vitro is intermediate to that of bupivacaine and lidocaine. '

Ropivacaine has been reported to be less toxic than bupivacaine but more toxic than lidocaine. ${ }^{2,3}$ After IV infusion of ropivacaine to volunteers, it was shown to be less toxic than bupivacaine in producing mild central nervous system and cardiovascular toxicity. ${ }^{4}$ Total plas$\mathrm{ma}$ and blood clearances of $0.50 \pm 0.12 \mathrm{~L} \cdot \mathrm{min}^{-1}$ and $0.72 \pm 0.16 \mathrm{~L} \cdot \mathrm{min}^{-1}$, an apparent volume of distribution (Vss) of $42 \pm 15$ and a terminal disposition half-life of $1.9 \pm 1.0 \mathrm{hr}$ has been reported after IV infusion of ropivacaine to volunteers. Plasma protein binding is high, 94 per cent, and most of the binding is accounted for by association with $\alpha_{1}$-acid glycoprotein. ${ }^{5}$

The main objective of this study was to assess the anaesthetic characteristics and pharmacokinetic properties of 0.5 per cent ropivacaine with or without epinephrine when used for brachial plexus anaesthesia in patients undergoing orthopaedic surgery. The clinical results of the study were reported separately ${ }^{6}$ and this report provides information on the plasma concentrations of ropivacaine that were produced.

\section{Methods}

This was an open label, nonrandomized trial which was part of a two-centre trial conducted at the University of Texas Health Science Center at San Antonio and the University of Illinois College of Medicine at Chicago. It was approved by the local Institutional Review Boards. The 17 patients included in the pharmacokinetic analysis were from the University of Texas Health Science Center at San Antonio.

The patients were ASA physical status I or II and scheduled to undergo upper extremity surgery under brachial plexus anaesthesia. Excluded from participating in the study were patients with a history of allergy to local anaesthetics of the amide type, significant neurological, cardiopulmonary or psychiatric disease, acute liver or renal disease, drug or alcohol abuse, and women of child-bearing age. Written informed consent was obtained from the patients and premedication was given with morphine $\left(0.15 \mathrm{mg} \cdot \mathrm{kg}^{-1} \mathrm{IM}\right)$ and midazolam (dose range of $0-3 \mathrm{mg}$ IV). Each patient then received a subclavian perivascular block according to the technique described by Winnie. ${ }^{7}$ After elicitation of a paraesthesia, one group of patients $(n=8)$ received 0.5 per cent ropivacaine without epinephrine and the other group $(n=9)$ received 0.5 per cent ropivacaine with epinephrine $1: 200,000$. Thirty-three $\mathrm{ml}$ of anaesthetic solution were used for the subclavian perivascular block and $5 \mathrm{ml}$ were used to block the intercostobrachial nerve in the axilla, which resulted in a total ropivacaine dose of $190 \mathrm{mg}$.

Concomitant medications given during anaesthesia included midazolam (ten patients), fentanyl (five patients) and diphenhydramine (one patient), which were all given for sedation. Other medications included cefazolin which was used prophylatically for surgery in four patients and metaclopramide which was given to one patient because of nausea.

Peripheral venous blood samples for analysis of ropivacaine plasma concentrations were drawn from a 16 . gauge catheter placed in the contralateral arm. The samples $(5 \mathrm{ml})$ were drawn into heparinized tubes at 0,5 , $10,15,20,25,30,45,60$ and $90 \mathrm{~min}$ and at $2,3,4,6,9$ and $12 \mathrm{hr}$ after the end of the ropivacaine injection. The plasma was separated by centrifugation and stored at $-20^{\circ} \mathrm{C}$ until assay.

The assay of ropivacaine in plasma was performed according to Osterlof et al. (Astra Pain Control AB, Sweden, technique to be published). Ropivacaine was extracted together with the internal standard, pentycaine (1-pentyl-2',6'-pipecoloxylidide) from alkalinized plasma with $n$-hexane + methylene chloride $(4+1)$. The extract was evaporated to dryness and the residue dissolved in a small volume of $n$-hexane + ethanol $(9+1)$. The content of ropivacaine was determined by gas chromatography, splitless injection, on a fused silica capillary column with crosslinked methyl silicone as stationary phase. Helium was used as a carrier gas with a nitrogen-sensitive detector. All concentrations are expressed as mg ropivacaine base per litre plasma. The limit of determination was $0.01 \mathrm{mg} \cdot \mathrm{L}^{-1}$ and the inter-assay precision obtained with 0.30 to $1.79 \mathrm{mg} \cdot \mathrm{L}^{-1}$ plasma was 7.9 to 6.7 per cent (coefficient of variation).

The peak plasma concentration of ropivacaine $\left(C_{\max }\right)$ and time to peak $\left(t_{\max }\right)$ were estimated from the observed concentration time points. The area under the plasma concentrations time curve (AUC) was calculated by the linear trapezoidal rule. The apparent first-order elimination rate constant and the corresponding half-life were calculated by conventional methods. ${ }^{8}$

The two ropivacaine groups were compared by use of a Wilcoxon rank sum test with $P<0.05$ considered statistically significant.

\section{Results}

Patient characteristics are listed in Table 1. Patient \#1 was replaced by patient \# 17 because of a broken ampule. Ropivacaine provided satisfactory analgesia in all patients but one, indicating a technically correct administration of ropivacaine. The block of patient \# I6 was inadequate for surgery and he was given a supplemental radial nerve 


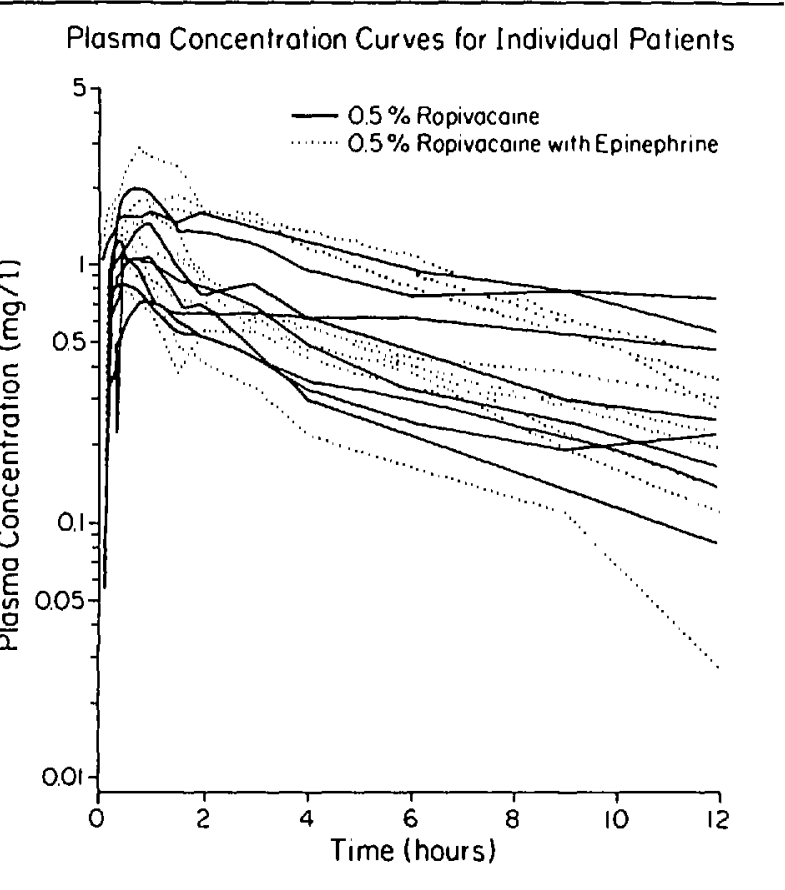

FIGURE I Plasma concentration of ropivacaine in individual patients after single administration of $33 \mathrm{ml} 0.5$ per cent ropivacaine (190 $\mathrm{mg}$ ) without and with epinephrine $(1: 200,000)$ for brachial plexus block.

block with 1.0 per cent mepivacaine with epinephrine 1:200,000. The patient is included in the analysis of plasma concentrations.

The mean $C_{\max }$ was $1.6 \mathrm{mg} \cdot \mathrm{L}^{-1}$ and $1.3 \mathrm{mg} \cdot \mathrm{L}^{-1}$ following the block after $190 \mathrm{mg}$ ropivacaine with and without epinephrine. The highest individual plasma concentration achieved was $2.9 \mathrm{mg} \cdot \mathrm{L}^{-1}$ with and $2.0 \mathrm{mg}$. $\mathrm{L}^{-1}$ without epinephrine. Median $\mathrm{t}_{\max }$ was $0.75 \mathrm{hr}$ and $0.88 \mathrm{hr}$ with similar ranges in both groups (Table II).

The individual plasma concentrations were within the same range regardless of whether ropivacaine was given with or without epinephrine (Figure 1). There was a tendency for higher plasma concentrations when ropivacaine was given with epinephrine (Table II, Figure 2) but the differences were not statistically significant (Table III).

In patient \#6 the plasma concentration showed a very slow decline at 6 to $12 \mathrm{hr}$ after injection. This precludes the estimation of a relevant terminal half-life during the observed time period in this patient. The slow decline of the plasma concentration (Figure 1) and, thus, long apparent half-lives of ropivacaine in patients \#4, 5 and 12 (Table II) probably reflect a slow systemic absorption of ropivacaine in these patients.

None of the patients in either group developed any adverse reactions suggesting cardiovascular or central
TABLE 1 Patient characteristics

\begin{tabular}{lcccc}
\hline Patient & Age & Sex & Body weight $(\mathrm{kg})$ & Height $(\mathrm{cm})$ \\
\hline \multicolumn{2}{l}{ With epinephrine } & & & \\
2 & 37 & $\mathrm{M}$ & 84 & 171 \\
3 & 40 & $\mathrm{M}$ & 60 & 173 \\
4 & 41 & $\mathrm{~F}$ & 77 & 153 \\
5 & 40 & $\mathrm{M}$ & 99 & 175 \\
6 & 36 & $\mathrm{~F}$ & 70 & 150 \\
7 & 54 & $\mathrm{M}$ & 58 & 182 \\
8 & 24 & $\mathrm{M}$ & 86 & 167 \\
17 & 37 & $\mathrm{M}$ & 100 & 185 \\
Mean & 38 & & 71 & 170 \\
SD & 11 & & 10 & 9 \\
& & & & \\
Without epinephrine & & & 168 \\
9 & 29 & $\mathrm{M}$ & 63 & 173 \\
10 & 23 & $\mathrm{M}$ & 68 & 180 \\
11 & 35 & $\mathrm{M}$ & 73 & 180 \\
12 & 43 & $\mathrm{M}$ & 95 & 163 \\
13 & 43 & $\mathrm{M}$ & 73 & 170 \\
14 & 40 & $\mathrm{M}$ & 75 & 152 \\
15 & 56 & $\mathrm{~F}$ & 66 & 170 \\
16 & 25 & $\mathrm{M}$ & 62 & 170 \\
18 & 44 & $\mathrm{M}$ & 62 & 170 \\
Mean & 39 & & 79 & 16 \\
SD & 8 & & 16 & \\
\hline & & & & \\
\hline
\end{tabular}

TABLE II Pharmacokinetic variables derived from plasma concentrations after $190 \mathrm{mg}$ ropivacaine without or with epinephrine for brachial plexus anaesthesia

\begin{tabular}{|c|c|c|c|c|c|}
\hline Patient & Epinephrine & $\begin{array}{l}C_{m a r} \\
\left(m g \cdot L^{-1}\right)\end{array}$ & $\begin{array}{l}t_{\max } \\
(h r)\end{array}$ & $\begin{array}{l}A \cup C_{0}-/ 2 h \\
\left(m g \cdot L^{-1} \cdot h r^{-1}\right)\end{array}$ & $\begin{array}{l}t \\
(h r)\end{array}$ \\
\hline 2 & - & 1.98 & 0.75 & 12.64 & 7.4 \\
\hline 3 & - & 1.07 & 1.0 & 3.96 & 4.3 \\
\hline 4 & - & 0.71 & 1.0 & 7.04 & 13.8 \\
\hline 5 & - & 0.85 & 0.5 & 3.95 & 13.5 \\
\hline 6 & - & 1.62 & 1.0 & 11.57 & $-\dagger$ \\
\hline 7 & - & 1.13 & 0.42 & 5.46 & 6.0 \\
\hline 8 & - & 1.48 & 1.0 & 6.57 & 5.4 \\
\hline 17 & - & 1.23 & 0.42 & 4.39 & 5.9 \\
\hline Mean & & 1.26 & $0.88^{*}$ & 6.95 & 8.0 \\
\hline SD & & 0.42 & & 3.39 & 3.9 \\
\hline 9 & + & 1.26 & 0.5 & 3.11 & 2.8 \\
\hline 10 & + & 1.87 & 1.5 & 11.40 & 5.0 \\
\hline 11 & + & 1.65 & 1.5 & 12.16 & 3.0 \\
\hline 12 & + & 1.02 & 0.5 & 6.07 & 11.1 \\
\hline 13 & + & 1.40 & 0.42 & 6.02 & 6.1 \\
\hline 14 & + & 2.91 & 0.75 & 13.26 & 6.0 \\
\hline 15 & + & 0.82 & 0.5 & 4.64 & 10.3 \\
\hline 16 & + & 2.11 & 0.75 & 6.36 & 3.8 \\
\hline 18 & + & 1.26 & 0.75 & 5.92 & 3.9 \\
\hline Mean & & 1.59 & $0.75^{*}$ & 7.66 & 5.8 \\
\hline SD & & 0.64 & & 3.63 & 3.0 \\
\hline
\end{tabular}

*Median.

$†$ Apparent steady-state conc 6-12 hr after dosing. 


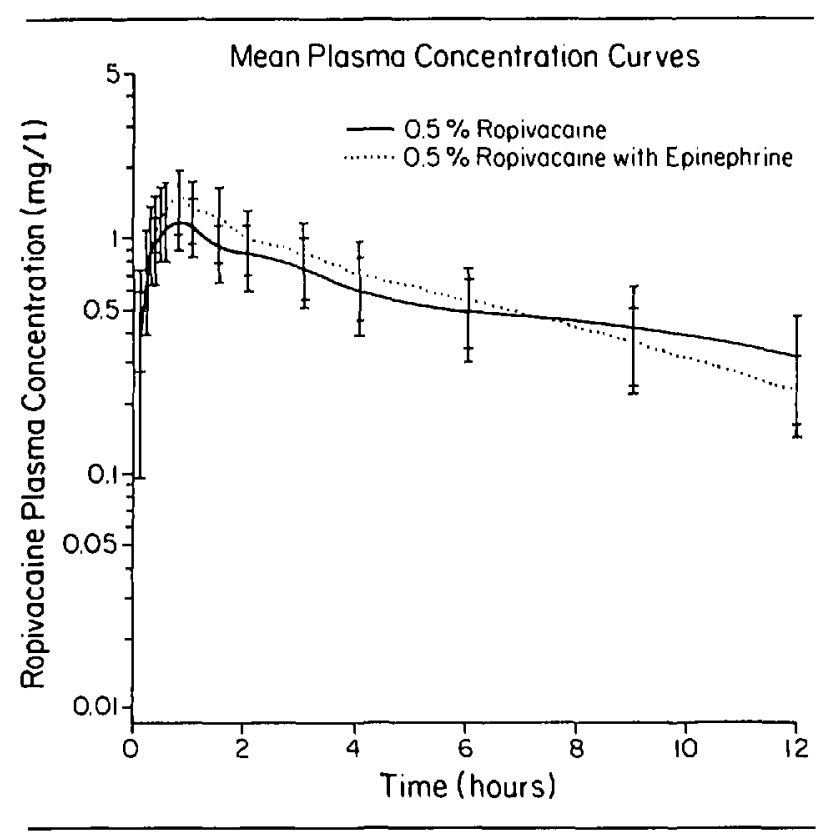

FIGURE 2 Mean (95 per cent confidence limits) plasma concentration of ropivacaine after single administration of $3.3 \mathrm{ml} 0.5$ per cent ropivacaine $(190 \mathrm{mg}$ ) withoul or with epinephrine $(1: 200,000)$ for brachial plexus block.

nervous system (CNS) toxicity. The ropivacaine dose ranged from $1.90-3.28 \mathrm{mg} \cdot \mathrm{kg}^{-1}$.

\section{Discussion}

Although previous studies have reported lower peak plasma concentrations of bupivacaine when epinephrine was added for brachial plexus block, ${ }^{9-11}$ this was not seen in the present study of ropivacaine. Ropivacaine seems to increase vascular smooth muscle activity and decrease blood flow at the site of injection over a wider range of concentrations compared with bupivacaine. ${ }^{2}$ Kopacz et $a l .^{12}$ showed that ropivacaine reduced, whereas bupivacaine increased, cutaneous blood flow in pigs. When epinephrine was added to ropivacaine, no further reduction in blood flow was seen. However, when epinephrine was added to bupivacaine it reduced the blood flow. If the lowering of plasma concentrations by the addition of epinephrine to local anaesthetics is due to a decrease in vascular absorption then one might predict that epineph-

TABLE III The 95\% confidence intervals (based on the Wilcoxon rank sum test) for the differences in pharmacokinetic variables derived from plasma concentrations after $190 \mathrm{mg}$ ropivacaine with or without epinephrine for brachial plexus anaesthesia

\begin{tabular}{lcccl}
\hline & $\begin{array}{l}C_{\max } \\
\left(m g \cdot L^{-1}\right)\end{array}$ & $\begin{array}{l}t_{\max } \\
(h r)\end{array}$ & $\begin{array}{l}A U C_{0}-12 h \\
\left(m g \cdot L^{-1} \cdot h r^{-1}\right)\end{array}$ & $\begin{array}{l}(j) \\
(h r)\end{array}$ \\
\hline Median & 0.22 & 0.10 & 0.60 & -2.05 \\
$95 \% \mathrm{Cl}$ & $-0.22,0.88$ & $-0.50,0.50$ & $-2.35,5.12$ & $-7.5,0.70$ \\
\hline
\end{tabular}

rine would reduce plasma levels of bupivacaine but would have little effect on plasma levels of ropivacaine. This may explain why epinephrine had no effect on the pharmacokinetic behaviour or on the blockade in the present study.

A terminal plasma half-life, of the order of $1.9 \mathrm{hr}$, has been reported after IV administration of ropivacaine. ${ }^{5}$ This suggests that the higher apparent half-life seen in this study after brachial plexus block reflects slow drug absorption. Thus, it is not possible to make a reliable estimate of the extrapolated AUC beyond the $12 \mathrm{hr}$ observation period, precluding an extended pharmacokinetic analysis of the results from the study.

The plasma concentrations following the block declined relatively slowly over the $12 \mathrm{hr}$ sampling period, which is consistent with the long duration of action of ropivacaine. ${ }^{6}$ The association between the apparent halflife in plasma and duration of block further suggests that the decline of plasma concentrations in these patients, at least to some extent, reflects the rate of systemic absorption of ropivacaine.

Scott $e t$ al. reported that when ropivacaine was given as a rapid IV infusion to volunteers, mild central nervous system symptoms were recorded in five of 12 subjects and appeared at venous plasma concentrations in the range of 1 to $2 \mathrm{mg} \cdot \mathrm{L}^{-1}$. However, the association between plasma concentration and symptoms was weak and the concentrations were often higher after the symptoms had disappeared. The reason for this may be that arterial and venous plasma concentrations had not reached equilibrium at the time of appearance of symptoms.

Although peak plasma concentrations of ropivacaine up to $2-3 \mathrm{mg} \cdot \mathrm{L}^{-1}$ were seen in some patients in this study, symptoms from the CNS were not observed. We cannot explain the difference in plasma concentrations and toxicity between our study and the data reported by Scolt et al. ${ }^{4}$ It should be noted, however, that the patients reported by Scott et al. ${ }^{4}$ were unpremedicated volunteers that had been familiarized with the CNS toxic effects of local anaesthetics. The patients in our study had no previous knowledge of toxic symptoms and were given midazolam, which may have contributed by masking such symptoms. In addition, the rapidity at which the plasma concentrations were achieved may also account for some differences in toxicity. The plasma levels noted in the study by Scott et al. ${ }^{4}$ were achieved rapidly following intravenous administration, whereas our plasma levels were achieved more slowly as the drug was released into the blood stream from the brachial plexus. It has been noted by Scott that peripheral venous plasma concentrations during rapid IV infusion are unreliable, particularly in relation to CNS changes, because of the large arteriovenous concentration differences that exist. ${ }^{4.13}$ The slower 
increase in plasma levels seen with brachial plexus block may allow more time for equilibration between arterial and venous concentrations. As central nervous system or cardiovascular symptoms attributed to the drug were not observed, brachial plexus block with $190 \mathrm{mg}$ ropivacaine seems safe.

\section{Acknowledgement}

Mrs. Monica Bjork, Astra Pain Control, Sweden, is acknowledged for skilful assistance in the assay of ropivacaine.

\section{References}

I Rosenberg PH, Kytta J, Alila A. Absorption of bupivacaine, ctidocaine, lignocaine and ropivacaine into n-heptane, rat sciatic nerve, and human extradural and subcutaneous fat. Br J Anaesth 1986; 58: 310-4.

2 Akerman $B$, Hellberg I-B, Trossvik $C$. Primary evaluation of the local anaesthetic properties of the amino amide agent ropivacaine (LEA 103). Acta Anaesthesiol Scand 1988; 32: $571-8$.

3 Reiz S, Haggmark S, Johansson G, Nath S. Cardiotoxicity of ropivacaine - a new amide local anaesthetic agent. Acta Anaesthesiol Scan 1989; 33: 93-8.

4 Scout DB, Lee A, Fagan D, Bowler GMR, Bloomfield P, Lundh $R$. Acute toxicity of ropivacaine compared with that of bupivacaine. Anesth Analg 1989; 69: 563-9.

5 Lee A, Fagan D, Lamont M. Tucker GT. Halldin M, Scont $D B$. Disposition kinetics of ropivacaine in humans. Anesth Analg 1989; 69: 736-8.

6 Hickey $R$, Candido KD, Ramamurthy $S$ et al. Brachial plexus block with a new local anaesthetic: 0.5 per cent ropivacaine. Can J Anaesth 1990; 37: 732-8.

7 Winnie AP. Perivascular techniques of brachial plexus block. In: Winnie AP (Ed.). Plexus Anesthesia. Philadelphia: W.B. Saunders, 1983; 145-63.

8 Gibaldi M, Perrier D. Pharmacokinetics. New York: Marcel Dekker, Inc., 1982.

9 Raj PP, Rosenblatt R, Miller J, Kalz RL, Carden E. Dynamics of local anesthetic compounds in regional anesthesia. Anesth Analg 1977; 56: 110-7.

10 Pihlajamaki $K K$, Lindberg RLP. Bupivacaine with and without adrenaline in interscalene brachial plexus blockade. Studies in patients with rheumatoid arthritis. $\mathrm{Br} \mathrm{J}$ Anaesth 1987; 59: 1420-4.
II Wildsmith JAW, Tucker GT, Cooper S, Scon DB, Covino $B G$. Plasma concentrations of local anaesthetics after interscalene brachial plexus block. Br J Anaesth 1977; 49: $461-6$.

12 Kopacz DJ, Carpenter RL, Mackey DC. Effect of ropivacaine on cutaneous capillary blood flow in pigs. Anesthesiology 1989; 71: 69-74.

13 Scott $D B$. Evaluation of clinical tolerance of local anaesthetic agents. Br J Anaesth 1975; 47: 328-33. 